Check for updates

Cite this: RSC Adv., 2018, 8, 33019

Received 21st July 2018

Accepted 4th September 2018

DOI: 10.1039/c8ra06169f

rsc.li/rsc-advances

\section{A ZnO/rice husk-based hollow carbonaceous nanosphere composite as an anode for high- performance lithium-ion batteries}

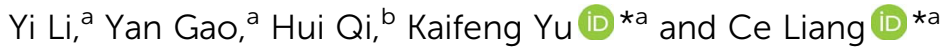

$\mathrm{ZnO}$ is considered as a substitute for the next generation of lithium ion battery anode materials because of its high volumetric energy density and abundant resources. In this work, we fabricate a new material that has nanorod-like $\mathrm{ZnO}$ distributed in a disorderly fashion on the surface of a rice husk-derived carbon skeleton. Rice husk as a carbon source is suitable for easing the pressure on the environment and improving the utilization of agricultural residues. Its unique interconnected hollow nanosphere structured skeleton provides better support for $\mathrm{ZnO}$ loading and electron transport. The $\mathrm{ZnO} /$ rice husk-based carbonaceous nanosphere composite samples were characterised by XRD, Raman, SEM and TEM. When used as an anode for lithium-ion batteries, the material exhibited promising Li storage properties and a high specific charge capacity of $920 \mathrm{~mA} \mathrm{~h} \mathrm{~g}^{-1}$ at $0.2 \mathrm{C}$ after 100 cycles.

\section{Introduction}

Lithium-ion batteries (LIBs) have gradually replaced the traditional battery because of their unique advantages such as high specific capacity, high operating voltage and environmentally friendly properties. With the extensive application of electric vehicles and the rapid development of high-tech, traditional energy storage devices have been unable to meet the requirements of the market. In order to develop new high-performance LIB anodes, transition metal oxide (TMO) materials based on alloying reactions, with high theoretical capacity, have been studied extensively in the past few years. Among the TMO anodes, $\mathrm{ZnO}$ has received much attention as it possesses

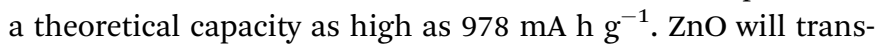
form to $\mathrm{Zn}$ upon redox reaction with $\mathrm{Li}^{+}\left(\mathrm{ZnO}+2 \mathrm{Li}^{+}+2 \mathrm{e}^{-} \leftrightarrow\right.$ $\left.\mathrm{Zn}+\mathrm{Li}_{2} \mathrm{O}\right),{ }^{1}$ and the following $\mathrm{Li}_{x} \mathrm{Zn}$ is formed by the alloying reaction $\left(\mathrm{Zn}+x \mathrm{Li}^{+}+x \mathrm{e}^{-} \leftrightarrow \mathrm{Li}_{x} \mathrm{Zn}(x \leq 1)\right){ }^{1}$ However, because of its high working potential, the structure of $\mathrm{ZnO}$ is easily broken down when a large volume change happens in the $\mathrm{Li}^{+}$insertion/ extraction process. Moreover, the destruction of the electrode structure results in relatively fast capacity attenuation. To overcome this problem, $\mathrm{ZnO}$ has been made with different morphologies with nanocrystallization and unique structures such as hierarchical flower-like ZnO nanospheres, a dumbbell like well-defined $\mathrm{ZnO}$ mesostructure, ultrathin $\mathrm{ZnO}$ nanotubes with well-organized hexagonal nanowalls and $\mathrm{ZnO}$ yolk-shell nanospheres have been established. ${ }^{2-5}$ These morphologies

${ }^{a}$ Key Laboratory of Automobile Materials, Ministry of Education, College of Materials Science and Engineering, Jilin University, Changchun 130025, PR China. E-mail: yukf@jlu.edu.cn; liangce@jlu.edu.cn

${ }^{b}$ The Second Hospital of Jilin University, Changchun 130041, PR China improve the electrochemical active area and guarantee good stability. In addition, another well-accepted method is to use fine assemblies of $\mathrm{ZnO}$ and carbon as LIB anodes, which obtain synergistic effects by combining the excellent conductivity of carbon and the high theoretical capacity of TMOs. ${ }^{6}$ Song et al. successfully synthesized hollow metal-organic frameworkderived porous $\mathrm{ZnO} / \mathrm{C}$ nanocages as anode materials for LIBs, which retained a high reversible capacity of $750 \mathrm{~mA} \mathrm{~h} \mathrm{~g}^{-1}$ after 100 cycles. $^{7}$ S. M. Abbas et al. prepared a hexagonal disk-shaped $\mathrm{ZnO} / \mathrm{CNT}$ composite as an anode material for LIBs and the reversible capacity stabilized at $602 \mathrm{~mA} \mathrm{~h} \mathrm{~g}^{-1}$ after 50 cycles. $^{8}$ Shen et al. synthesized $\mathrm{ZnO}$-loaded/porous carbon composites that displayed an outstanding reversible capacity of $653.7 \mathrm{~mA} \mathrm{~h} \mathrm{~g}^{-1}$ after 100 cycles. $^{9}$

Carbon is one of the most representative LIB anode materials. Nowadays, much effort is devoted to the study of biomass carbon materials, such as peanut shell, ${ }^{\mathbf{1 0}}$ starch and oak, ${ }^{\mathbf{1 1}}$ lignin, cotton, ${ }^{\mathbf{1 2}}$ wool, ${ }^{\mathbf{1 3}}$ rice husk and sugar. ${ }^{\mathbf{1 4}}$ The development of new renewable energy sources is an effective way to solve environmental problems instead of burning agricultural waste in fields leading to air and soil pollution. The interiors of biomass materials, through activation, can be used to produce a large amount of microporous and mesoporous structures owing to their natural pores and activity. Of the various kinds of biomass materials, rice husk (RH) is one of the major byproducts of the agricultural industry with an amazing amount of $\sim 2.9 \times 10^{7}$ t produced per year all over the globe. ${ }^{15} \mathrm{RH}$ is light, bulky, and highly porous and is mainly composed of cellulose (38\%), lignin (22\%), hemicellulose $(18 \%)$ and $\mathrm{SiO}_{2} \cdot{ }^{16}$ This unique structure results in a distinct skeleton and pores in the conversion of organic matter to polymer compounds. ${ }^{\mathbf{1 7}}$ Porous carbon prepared from rice husk has been gradually 
applied to industrial production. Y. Gao et al. employed porous carbon made from rice husk as an electrode material for an electrochemical double layer capacitor. The material showed high-power handling ability and electrochemical cycle performance, and after 30000 cycles the capacitive value remained almost unchanged. ${ }^{18}$ A biomass carbon material prepared with RH has been successfully used for the anode electrode of LIBs. $\mathrm{Yu}$ et al. ${ }^{19}$ synthesized a novel carbonaceous material with an interconnected hollow nanospheres structure, and the reversible specific capacity stabilized at $489 \mathrm{~mA} \mathrm{~h} \mathrm{~g}{ }^{-1}$ after 100 cycles at a rate of $0.2 \mathrm{C}$ ( $1 \mathrm{C}$ refers to the current of the rated capacity of the battery).

In recent years, hollow structures have received great attention in the general synthesis of active materials because of their unique properties in LIBs such as high surface-to-volume ratios, and excellent thermal and chemical stabilities. ${ }^{20-23}$ Inspired by this proposal, we herein report a facile and convenient way to fabricate $\mathrm{ZnO}$ nanorods connected to the surface of an amorphous carbon skeleton prepared from RH-cellulose (RHC). In pretreatment, the silica and lignin were removed by alkali treatment and acid treatment, and the as-prepared cellulose had a large number of functional groups on its surface, which were connected to $\mathrm{ZnO}$ nanorods by electrostatic interactions under hydrothermal conditions. This material was expected to have a large surface and high capacity. This work may provide a general approach for preparing TMOs and RHC composites.

\section{Experimental}

\subsection{Material preparation}

The reagents, zinc acetate $\left(\mathrm{Zn}(\mathrm{OAc})_{2}\right)$, cetyltrimethylammonium (CTAB), sodium hydroxide $(\mathrm{NaOH})$, ethylenediamine (EDA), and ethanol used in the experiments were of analytical grade. Rice husks (RH) were obtained as a by-product of rice harvested from Changchun, Jilin province, China.

\subsection{Preparation of $\mathrm{ZnO}$}

First, $0.11 \mathrm{~g} \mathrm{Zn}(\mathrm{OAc})_{2}, 0.18 \mathrm{~g}$ CTAB, $0.04 \mathrm{~g} \mathrm{NaOH}$, and $0.07 \mathrm{ml}$ EDA were dissolved in $10 \mathrm{ml}$ of ethanol respectively with constant magnetic stirring for $10 \mathrm{~min}$, and then the CTAB, $\mathrm{NaOH}$ and EDA solutions were added to the stirred $\mathrm{Zn}(\mathrm{OAc})_{2}$ solution sequentially, and the solution was continuously stirred for $30 \mathrm{~min}$ and hydrothermally treated at $180{ }^{\circ} \mathrm{C}$ for $6 \mathrm{~h}$. The white product was collected and washed with deionized water several times. After this, it was finally dried at $60^{\circ} \mathrm{C}$ for $12 \mathrm{~h}$, and ZnO was obtained.

\subsection{Preparation of $\mathrm{RHC} / \mathrm{ZnO}$}

$2 \mathrm{~g}$ RH was washed with deionized water and dried. Then, it was transferred into a $50 \mathrm{ml}$ Teflon-lined stainless steel autoclave with $2 \mathrm{M} \mathrm{NaOH}$ and kept at $180{ }^{\circ} \mathrm{C}$ for $12 \mathrm{~h}$. After cooling, the precipitates were taken out and washed with deionized water to ensure a neutral $\mathrm{pH}$, and then refluxed with $2 \mathrm{M} \mathrm{HCl}$ at $80^{\circ} \mathrm{C}$ for $2 \mathrm{~h}$. When the $\mathrm{pH}$ of the solution was adjusted to neutral with deionized water, the solution ( $\mathrm{RHC}$ and $\mathrm{ZnO}$ ) was transferred to a Teflon-lined stainless steel autoclave, and maintained at
$200{ }^{\circ} \mathrm{C}$ for $24 \mathrm{~h}$. After cooling down to room temperature, the precipitates were collected by centrifugation, washed with ethanol, and dried at $60{ }^{\circ} \mathrm{C}$ for $6 \mathrm{~h}$. Finally the composite was calcinated in an $\mathrm{Ar}$ atmosphere at $500{ }^{\circ} \mathrm{C}$ with a heating rate of $5{ }^{\circ} \mathrm{C} \min ^{-1}$ for $3 \mathrm{~h}$. The as-obtained product was denoted RHC/ $\mathrm{ZnO}$.

\subsection{Characterization and electrochemical properties}

The crystal structure of the samples was determined using XRD with a Siemens D5000 X-ray Diffractometer with nickel-filtered $\mathrm{Cu} \mathrm{K} \alpha$ radiation. The structure and morphology of $\mathrm{RHC} / \mathrm{ZnO}$ were observed by energy dispersive spectrometry (EDS) and field emission scanning electron microscopy (JEOL JSM-6700F). The microstructures and morphologies of the samples were investigated with transmission electron microscopy (TEM). Raman spectra were recorded on a Renishaw inVia instrument.

\subsection{Electrochemical characterization}

The working electrode was prepared by mixing $80 \mathrm{wt} \%$ active material with $10 \mathrm{wt} \%$ acetylene black and $10 \mathrm{wt} \%$ polyvinylidene difluoride (PVDF) to form a homogenous slurry. The slurry was coated on copper foil disks and dried $12 \mathrm{~h}$ in a vacuum oven at $120^{\circ} \mathrm{C}$. The CR2025 coin cells were assembled in an Ar-filled glovebox with Celgard polypropylene as a separator. Galvanostatic charge and discharge tests were performed at room temperature on a LAND CT-2001 battery tester, while extraction tests were carried out between $0.01 \mathrm{~V}$ and $3 \mathrm{~V}$. Cyclic voltammetry (CV) and electrochemical impedance spectroscopy (EIS) tests were performed on a CH650D electrochemical workstation. CV tests were carried out at a scan rate of $0.1 \mathrm{mV}$ $\mathrm{s}^{-1}$ within a test voltage range of $0-3 \mathrm{~V}$. EIS measurements were performed over a frequency range between $100 \mathrm{kHz}$ and $0.1 \mathrm{~Hz}$ with an applied voltage of $5 \mathrm{mV}$.

\section{Results and discussion}

Fig. 1a shows XRD patterns of the $\mathrm{ZnO}$ and the $\mathrm{ZnO} / \mathrm{RHC}$ composite. The diffraction peaks appearing at $31.80^{\circ}, 34.48^{\circ}$, $36.21^{\circ}, 47.64^{\circ}, 56.60^{\circ}, 62.86^{\circ}, 66.45^{\circ}, 68.00^{\circ}, 69.04^{\circ}, 72.70^{\circ}$ and $77.00^{\circ}$, correspond to (100), (002), (101), (102), (110), (103), (200), (112), (201), (004) and (202), which can be indexed as the wurtzite phase of hexagonal ZnO (JCPDS no. 36-1451). The diffraction peaks of $\mathrm{ZnO}$ are sharp and intense, indicating its
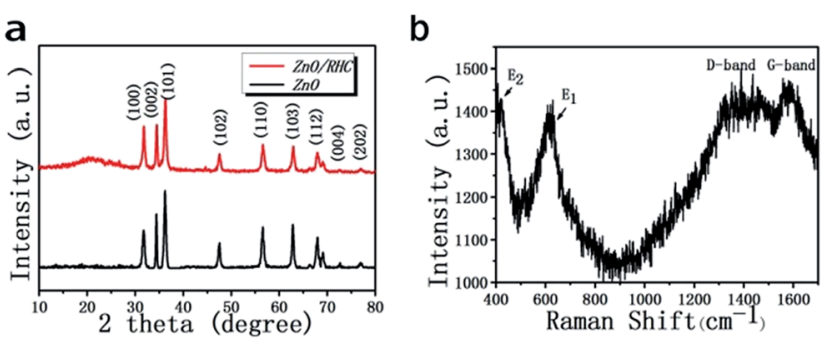

Fig. 1 (a) XRD patterns of $\mathrm{RHC} / \mathrm{ZnO}$ and pure $\mathrm{ZnO}$. (b) Raman spectrum of $\mathrm{RHC} / \mathrm{ZnO}$. 
highly crystalline nature. No impurity peaks are observed, confirming the high purity of the products. It should be noted that the broad peak at $\mathrm{ca} .20^{\circ}$ observed for $\mathrm{ZnO} / \mathrm{RHC}$ corresponds to amorphous carbon, and there is no impurity in the composite.

In order to confirm the presence of well-graphitized carbon in the $\mathrm{RHC} / \mathrm{ZnO}$ composite, Raman spectroscopic investigations were also conducted. As shown in Fig. 1b, the E1 (LO) mode (ca. $610 \mathrm{~cm}^{-1}$ ) is attributed to structural defects of $\mathrm{ZnO}$, and the peak $\left(440 \mathrm{~cm}^{-1}\right)$ corresponds to the E2 (high) mode which is a characteristic of the hexagonal wurtzite phase. Peaks at $1380 \mathrm{~cm}^{-1}$ and $1595 \mathrm{~cm}^{-1}$ are also observed, which could be assigned to the presence of the $\mathrm{D}$ band and $\mathrm{G}$ band. The $\mathrm{D}$ band is for $\mathrm{sp}^{3}$ defects or disorder in carbon. ${ }^{24}$ The $\mathrm{G}$ band corresponds to in-plane vibrations of $\mathrm{sp}^{2}$-bonded carbon atoms. ${ }^{25}$ The disorder degree of the amorphous material and the average size of the $\mathrm{sp}^{2}$ domains were measured by the $I_{\mathrm{D}} / I_{\mathrm{G}}$ intensity ratio. ${ }^{26}$ The ratio of $\mathrm{RHC} / \mathrm{ZnO}$ was calculated to be 0.86 , which corresponds to an increasing degree of ordered $\mathrm{sp}^{2}$ bonded carbon and a decreasing number of defects and vacancies due to the $\mathrm{ZnO}$ compound nanoparticles on the carbon matrix.

The detailed structures of $\mathrm{ZnO}$ and $\mathrm{ZnO} / \mathrm{RHC}$ are shown in Fig. 2. It is clearly displayed in Fig. 2(a) and (b) that most ZnO nanorods are disorderly and unsystematic and are anchored on the amorphous three-dimensional skeleton. A high magnification FESEM image of the sample reveals that RHC with an amorphous stereoscopic structure is connected to $\{11-20\}$ plane surfaces of the $\mathrm{ZnO}$ nanorods. When zooming in, a large number of small $\mathrm{ZnO}$ particles with diameters of $20 \mathrm{~nm}$ can be

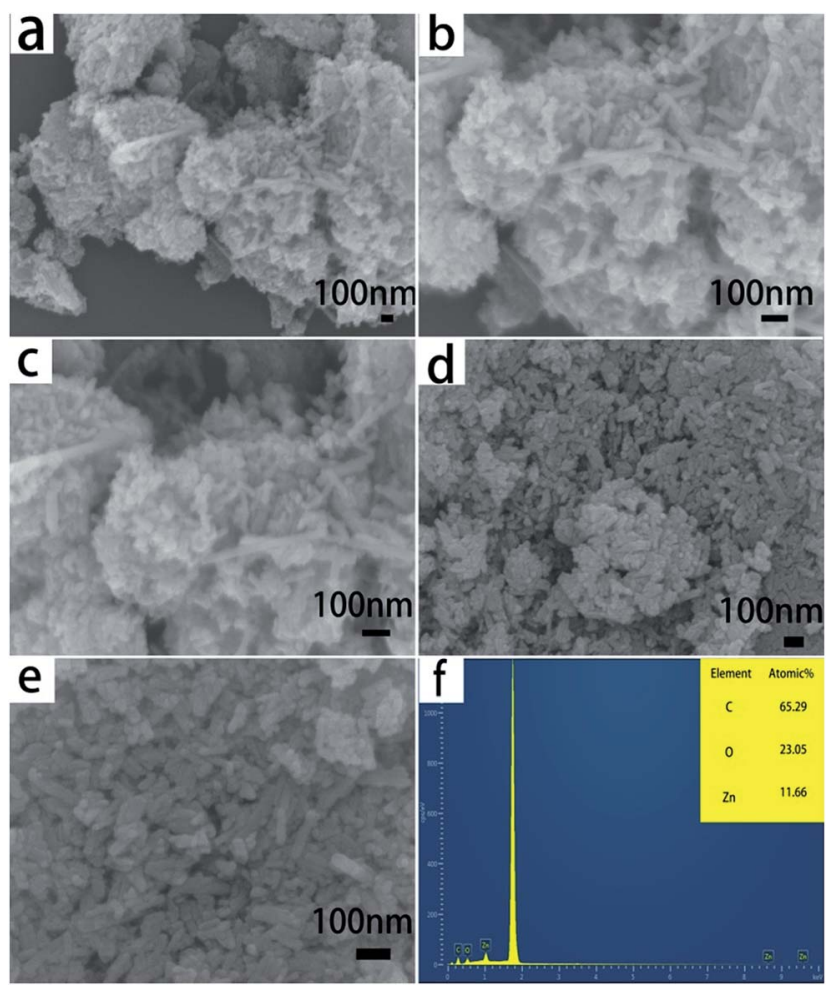

Fig. $2(a-c)$ The FESEM images of $\mathrm{ZnO} / \mathrm{RHC}$. ( $d$ and e) The FESEM images of $\mathrm{ZnO}$. (f) The SEM-mounted EDS spectrum. observed. These small sizes are favorable to lithium ion intercalation/deintercalation. ${ }^{27}$ The three-dimensional skeleton of RHC can buffer the volume expansion of $\mathrm{ZnO}$ nanorods and improve the stability of the $\mathrm{ZnO} / \mathrm{RHC}$ composite. Obviously, the particles of pure $\mathrm{ZnO}$ are found to be nanorod crystals, as shown in Fig. 2(d) and (e), with an average diameter of $20 \mathrm{~nm}$ and a length of $100 \mathrm{~nm}$. From the SEM-mounted EDS spectrum in Fig. 2(f), we can see that only $\mathrm{C}, \mathrm{O}$ and $\mathrm{Zn}$ exist in the composite. The highest peak of the EDS is the measurement of silicon negative film. Although the determination of the carbon content by EDS has high uncertainty due to its low atomic weight, ${ }^{28}$ combined with the XRD, it still can indicate that $\mathrm{ZnO}$ nanorods have been successfully embedded in the surface of the carbon matrix.

In order to determine the crystal growth behavior, the $\mathrm{ZnO}$ nanorods grown on the surface of an amorphous carbon block were further characterized by TEM and HRTEM. As can be seen from Fig. 3a and b, the nanorod-like $\mathrm{ZnO}$ is well dispersed on the surface of the three-dimensional amorphous skeleton composed of many hollow nanostructures of carbon spheres. The sizes of the carbon hollow nanospheres with diameters ranging from 20 to $150 \mathrm{~nm}$ are interconnected closely. The insets of (b) and (c) are partial enlarged views of the hollow carbon spheres. This hollow structure provides a greater contact area for the electrode material and the electrolyte, accelerating the transfer of electrons and lithium ions, while providing protection for the volume change of ZnO. The HRTEM image of $\mathrm{ZnO} / \mathrm{RHC}$ (Fig. 3d) reveals that the lattice fringes of $\mathrm{ZnO}$ display interplanar spacings of $0.26 \mathrm{~nm}$ in the particles, which match
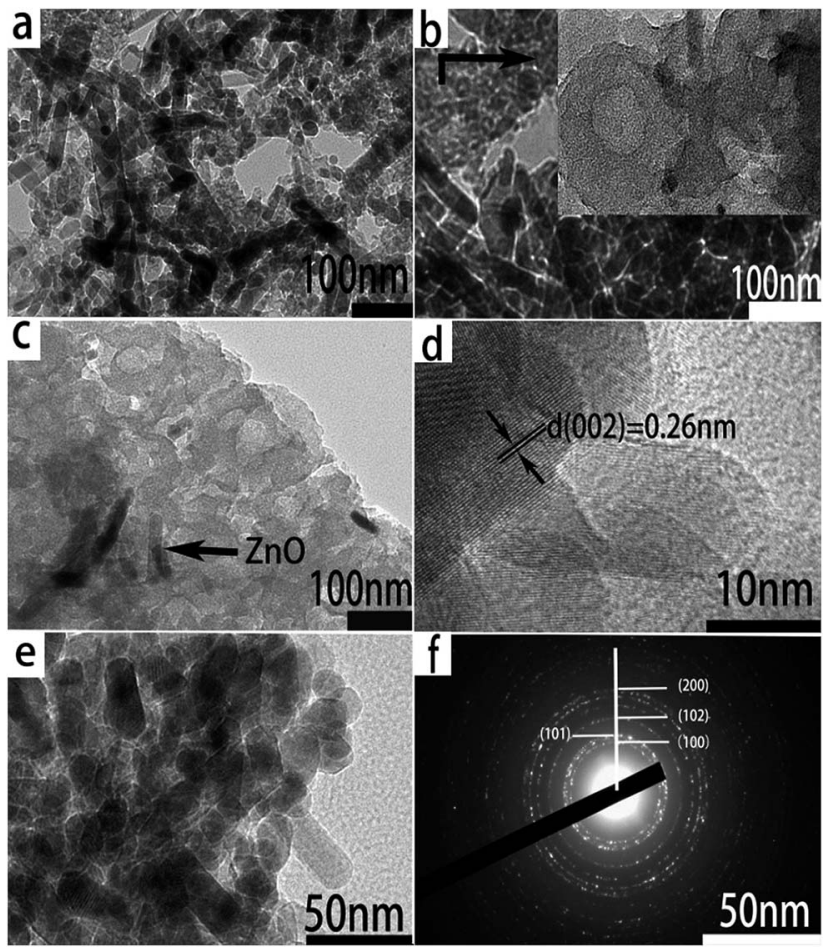

Fig. 3 ( $a$ and b) TEM images of the RHC/ZnO. (c and d) HR-TEM images of the RHC/ZnO. (e) TEM image of $\mathrm{ZnO}$. (f) SAED pattern of $\mathrm{RHC} / \mathrm{ZnO}$ 
well respectively with those of the (002) planes of hcp $\mathrm{ZnO}$. Fig. 3e shows a typical TEM image of the synthesized $\mathrm{ZnO}$ nanorods, which are of a hexagonal crystal system. Most of the nanorods have straight sides and regular ends. A particle count taken from many such images, obtained from different regions of the sample, confirmed the presence of an essentially monodispersed arrangement. The SAED pattern (Fig. 3f) depicts the observed lattice fringes with lattice distances of $0.2785 \mathrm{~nm}$, $0.2477 \mathrm{~nm}, 0.2024 \mathrm{~nm}$ and $0.1437 \mathrm{~nm}$, which correspond to the (100), (101), (102), and (200) facets of the ZnO polycrystalline phase. ${ }^{29}$ This is consistent with the XRD and Raman analysis.

Fig. 4 illustrates the formation of RHC/ZnO. First, silica and lignin are removed from the $\mathrm{RH}$ in a high-temperature alkaline solution, and after acid treatment, cellulose is obtained. Then, during a hydrothermal carbonization process, most of the cellulose is hydrolyzed to glucose under high temperature and high pressure to form hydroxymethyl furfural by tautomerization and intramolecular dehydration. After a series of polymerization and polycondensation reactions, a crosslinked furan compound is generated. ${ }^{30}$ As the reaction goes on, small molecules, as shown in the figure, are gradually precipitated and form the nuclei of carbon nanospheres. The spherules gradually accumulate and become larger to reduce the free energy of the surface. During the growth of the spheres, a large number of defects are generated in the interior, and a hollow structure is formed, with the RHC successfully prepared at the end. ${ }^{19}$ The growth process of the $\mathrm{ZnO}$ nanorods occurs with $\mathrm{Zn}(\mathrm{OH})_{2}$ forming the growth unit $\mathrm{Zn}(\mathrm{OH})_{4}{ }^{2-}$ by hydrolysis in alkaline conditions. CTAB acts as a cationic surfactant and reduces the free energy of the interface, which is conducive to the formation of crystal nuclei. As shown in the figure, CTAB and $\mathrm{Zn}(\mathrm{OH})_{4}{ }^{2-}$ form an ion pair. The nucleation arises from the oxolation of the growth unit and the protonation of the anions. Hydrophobic films formed by CTAB during the growth process lead to its anisotropy. The formation of nanorods is ensured by the surface-bonding method on the (0001) face. The hydroxyl groups on RHC and the $\mathrm{Zn}^{2+}$ on the $\{11-20\}$ planes will be bound together by electrostatic interactions, and carbonization results in the final formation of $\mathrm{RHC} / \mathrm{ZnO}$.

In addition, the content of $\mathrm{ZnO}$ in the composite was estimated by thermal gravimetric (TG) analysis, TG was performed from room temperature to $900{ }^{\circ} \mathrm{C}$ in air with a heating rate of $10^{\circ} \mathrm{C} \min ^{-1}$. There was a weight loss below $200{ }^{\circ} \mathrm{C}$ caused by the removal of physically absorbed water. A significant weight loss

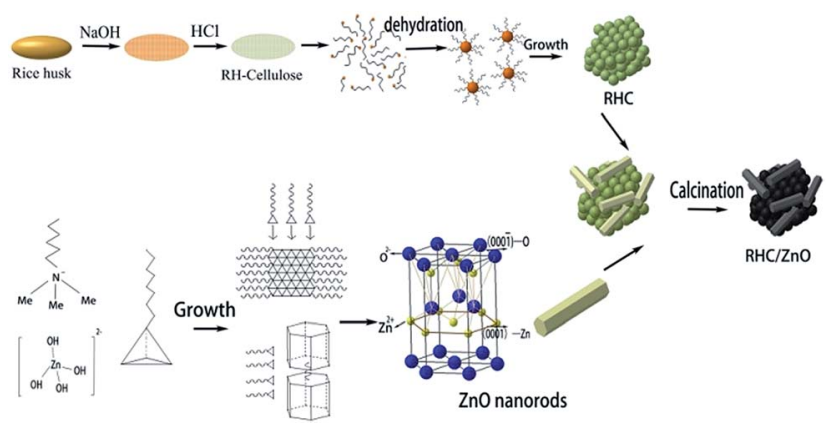

Fig. 4 Schematic illustration of the synthesis process of $\mathrm{ZnO} / \mathrm{RHC}$. of $42.2 \mathrm{wt} \%$ was recorded at about $400{ }^{\circ} \mathrm{C}$, which indicates that the content of carbon in the $\mathrm{ZnO} / \mathrm{RHC}$ was $42.2 \mathrm{wt} \%$ (Fig. 5).

The electrical performance behaviors of the $\mathrm{ZnO} / \mathrm{RHC}$ anodes were tested by CV (Fig. 6a). In the first cathodic scan, the $\mathrm{CV}$ curves present two obvious reduction peaks at around 0.2 and $0.8 \mathrm{~V}$. The peak located at $0.2 \mathrm{~V}$ is related to the conversion process of $\mathrm{ZnO}$ to LiZn alloy, and the $0.8 \mathrm{~V}$ peak can be attributed to the formation of the partially reversible solid electrolyte interphase (SEI) layer. ${ }^{31}$ The peak at $\sim 1.5 \mathrm{~V}$ is related to the reactions between lithium ions and functional groups on the surface of the material as reported previously. ${ }^{19}$ After the subsequent cathodic sweeps, a strong cathodic peak shift to $0.8 \mathrm{~V}$, which becomes broader, corresponds to the reduction of $\mathrm{ZnO}$ to $\mathrm{Zn}$ and the formation of the alloy. ${ }^{32}$ An oxidation peak is located in the potential range of 0-0.5 V during the first and the subsequent anodic scans, which may be ascribed to the dealloying process of the LiZn alloy. ${ }^{33}$ The broad peak located at about $1.35 \mathrm{~V}$ can be related to the formation of $\mathrm{ZnO}$ by the redox reaction between $\mathrm{Zn}$ and $\mathrm{Li}_{2} \mathrm{O} .{ }^{34}$ After the first cycle, the curves

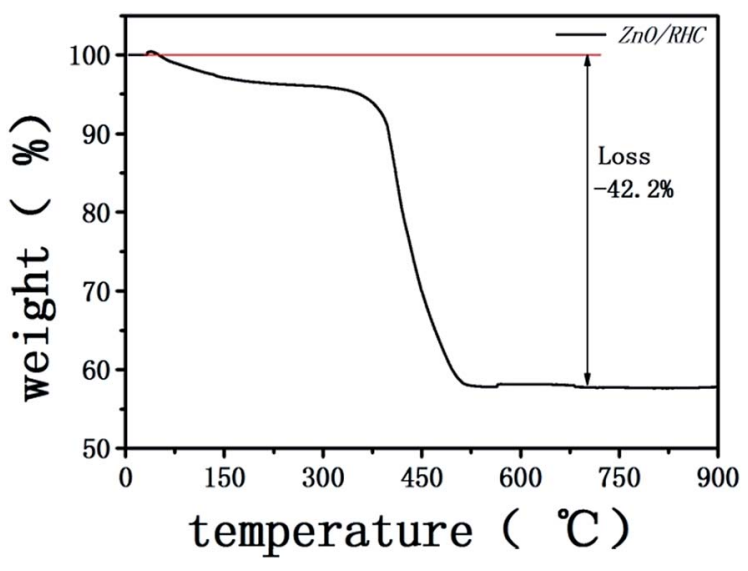

Fig. $5 \mathrm{TG}$ curve of $\mathrm{ZnO} / \mathrm{RHC}$ in an air atmosphere. a

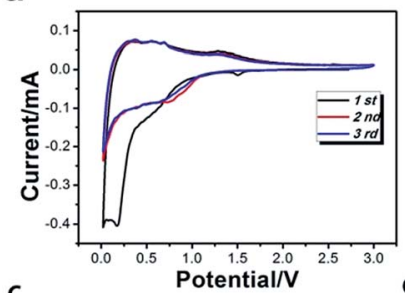

C

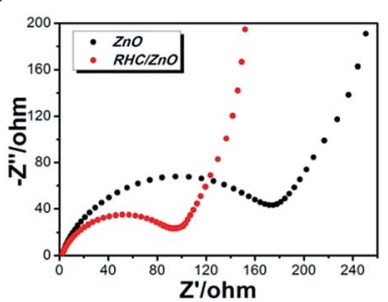

b

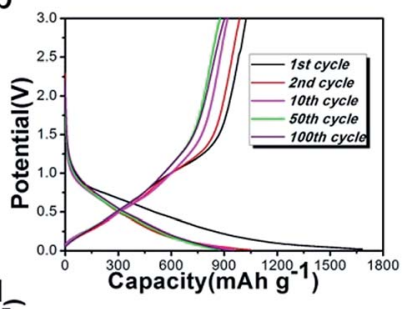

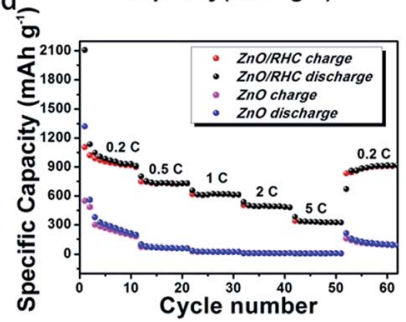

Fig. 6 (a) Cyclic voltammogram curves of $\mathrm{ZnO} / \mathrm{RHC}$. (b and c) Nyquist plots for $\mathrm{ZnO} / \mathrm{RHC}$ and $\mathrm{ZnO}$. (d) The rate performance of the $\mathrm{ZnO}$ and $\mathrm{ZnO} / \mathrm{RHC}$. 
almost overlap in subsequent cycles indicating that $\mathrm{ZnO} / \mathrm{RHC}$ have good stability and reversibility.

Fig. $6 \mathrm{~b}$ shows the charge-discharge curves of $\mathrm{ZnO} / \mathrm{RHC}$ at a current density of $0.2 \mathrm{C}$ in the range of $0.01-3 \mathrm{~V}$ in the $1 \mathrm{st}, 2 \mathrm{nd}$, 10 th, 50th and 100th cycles. It was noticed that the first discharge and charge capacities reached maxima of $1679.7 \mathrm{~mA} \mathrm{~h} \mathrm{~g}^{-1}$ and $1024.1 \mathrm{~mA} \mathrm{~h} \mathrm{~g}^{-1}$, showing a coulombic efficiency of $70.0 \%$. A pronounced plateau around $0.8 \mathrm{~V}$ and a long flat plateau at $0.25 \mathrm{~V}$ in the first discharge curve are attributed to the decomposition of the electrolyte to generate the SEI layer and the reactions between $\mathrm{Zn}$ and $\mathrm{Li}^{+}$to form LiZn alloys. ${ }^{35}$ These results match the $\mathrm{CV}$ characterization. Besides, the coulombic efficiency is also increased to $94.3 \%, 96.6 \%, 99.7 \%$ and $99.5 \%$ in the 2 nd, 10 th, 50 th and 100th cycles, indicating that the reactions become more reversible and steady. ${ }^{36}$

To further determine the electrochemical behaviors of the hybrid materials, EIS tests were performed. Fig. 6c shows Nyquist plots for the fully cycled cells. Apparently, the diameter of the medium-frequency semicircle for RHC/ZnO $\left(R_{\mathrm{ct}}=\sim 95 \Omega\right)$ is much smaller than that for $\mathrm{ZnO}\left(R_{\mathrm{ct}}=\sim 175 \Omega\right)$, demonstrating that the introduced RHC can further improve the electronic conductivity of the active substance and thereby give rise to improved electrochemical performance in LIBs. ${ }^{37} \mathrm{RHC}$, where $\mathrm{ZnO}$ nanorods are dispersed, is equivalent to a skeleton with an amorphous structure, which is conducive to stress relaxation. It is possible to effectively prevent the aggregation and pulverization of the $\mathrm{ZnO}$ particles during the charging and discharging processes.

In order to further investigate the rapid transfer of lithium ions and capacity recovery, Fig. $6 \mathrm{~d}$ displays the rate capabilities of the $\mathrm{ZnO}$ nanorods and the $\mathrm{ZnO} / \mathrm{RHC}$ at various current densities. The $\mathrm{ZnO} / \mathrm{RHC}$ cell was first tested for 10 cycles at rates of $0.2,0.5,1,2$ and $5 \mathrm{C}\left(1 \mathrm{C}=978 \mathrm{~mA} \mathrm{~h} \mathrm{~g}^{-1}\right)$, and the corresponding reversible capacities were 931.9, 729.6, 617.6, 491.4 and $325.7 \mathrm{~mA} \mathrm{~h} \mathrm{~g}^{-1}$, respectively, returning to a cycle rate of $0.2 \mathrm{C}$ for 60 cycles, where the capacity could revert to $927.2 \mathrm{~mA} \mathrm{~h}^{-1}$. It presented excellent rate cyclic performance, because there was no significant capacity loss at each rate test. These results further suggest the good reversibility of the electrode materials and the occurrence of reactivation. ${ }^{38}$ In order to investigate the role that RHC played in the electrode performance, pure $\mathrm{ZnO}$ nanorods were also tested under the same electrochemical conditions. As we can see, the rate capability of $\mathrm{ZnO}$ with the additive of RHC was better than that of $\mathrm{ZnO}^{39}$ The superior cycle and rate performances of $\mathrm{ZnO} / \mathrm{RHC}$ can be ascribed to the synergistic interactions between $\mathrm{ZnO}$ and carbon.

Fig. 7 shows the discharge-charge cycling performances of the $\mathrm{ZnO} / \mathrm{RHC}$ composite and $\mathrm{ZnO}$ particles at a rate of $0.2 \mathrm{C}$ for 100 cycles. It was noted that the $\mathrm{ZnO} / \mathrm{RHC}$ electrode exhibits a high and reversible capacity of $920 \mathrm{~mA} \mathrm{~h} \mathrm{~g}^{-1}$ even after 100 cycles. The capacities of the $\mathrm{ZnO}$ particles decrease from $576 \mathrm{~mA} \mathrm{~h} \mathrm{~g}^{-1}$ to $45.5 \mathrm{~mA} \mathrm{~h} \mathrm{~g}^{-1}$. Such a rapid decline in the process was due to the pulverization of $\mathrm{ZnO}$. So, it is obvious that the carbon framework derived from RHC plays a crucial role in the enhanced electrochemical performance. The specific advantages can be summarized as follows: (a) the $\mathrm{ZnO}$ nanorods can boost the electrochemical kinetics and shorten the

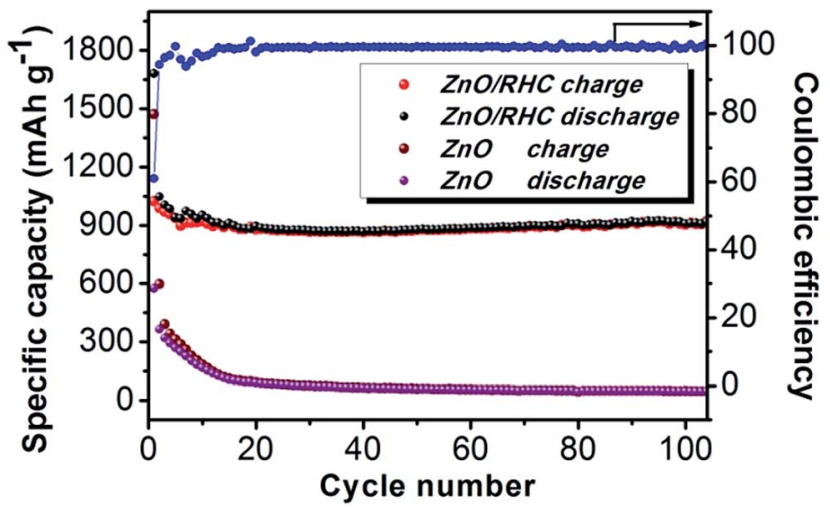

Fig. 7 Cycling performance profiles of $\mathrm{ZnO} / \mathrm{RHC}$ and $\mathrm{ZnO}$ at a rate of $0.2 \mathrm{C}$ and the coulombic efficiency of $\mathrm{ZnO} / \mathrm{RHC}$.

Table 1 Comparison of the cycling performances of RHC and previously reported $\mathrm{ZnO}$ based anode materials

\begin{tabular}{lllll}
\hline & $\begin{array}{l}\text { Current } \\
\text { density } \\
\left(\mathrm{mA} \mathrm{g}^{-1}\right)\end{array}$ & $\begin{array}{l}\text { Capacity } \\
\left(\mathrm{mA} \mathrm{h} \mathrm{g}^{-1}\right)\end{array}$ & $\begin{array}{l}\text { Cycle } \\
\text { number }\end{array}$ & Ref. \\
\hline RHC & $\begin{array}{l}0.2 \mathrm{C} \\
(1 \mathrm{C}=\end{array}$ & 489 & 100 & 18 \\
& $\left.372 \mathrm{~mA} \mathrm{~g}^{-1}\right)$ & & & \\
ZnO-C microspheres & 100 & 520 & 150 & 40 \\
ZnO@graphene & 200 & 360 & 200 & 41 \\
ZnO/Cu/CNFs & 100 & 812 & 50 & 42 \\
ZnO-NiO-Co $\mathrm{O}_{4}$ & 500 & 1060 & 300 & 43 \\
$\begin{array}{l}\text { ZnO-NiO hybrid } \\
\text { microspheres }\end{array}$ & 100 & 1176 & 200 & 44 \\
$\begin{array}{l}\text { ZnO/Ni/C hollow } \\
\text { microspheres }\end{array}$ & 100 & 583 & 20 & 45 \\
& & & &
\end{tabular}

diffusion distances of lithium ions and electrons. ${ }^{40}$ (b) The skeleton of the three-dimensional hollow carbon nanospheres provides a larger contact area, which is also beneficial to the diffusion and transfer of electrons and lithium ions, as well as reducing the transfer path effectively. The most important thing is that the electrical conductivity of the whole electrode material is improved during the electrochemical process. (c) The $\{11-20\}$ planes of the $\mathrm{ZnO}$ nanorods are connected uniformly to the surface of the RHC, which makes the contact area more stable, as well as suppressing pulverization and maintaining the integrity of hexagonal $\mathrm{ZnO}$ to achieve a stable charge-discharge cycle. (d) Due to the fact that a larger specific surface area possesses more reversible lithium storage sites, this suggests that it has more interfacial charge storage. ${ }^{\mathbf{1 6}}$

Table 1 gives the results of performance comparisons of recent reports based on $\mathrm{ZnO}$ and $\mathrm{RHC}$ electrodes, which show that the electrode we prepared displays good electrochemical performance.

\section{Conclusions}

In summary, the whole synthesis process was simple and convenient. By using the carbonaceous biomass of rice husk 
and $\mathrm{ZnO}$ nanorods as a lithium ion anode material, this research achieves a high specific capacity and a stable cycle number. The unique skeleton of the three-dimensional hollow carbon nanospheres plays a significant role in the charge and discharge process. The problems of volume expansion of $\mathrm{ZnO}$ caused by rapid decay and the electronic conductivity of the electrodes were solved. The synergistic effects of RHC and $\mathrm{ZnO}$ meant that the material could maintain a capacity of $920 \mathrm{~mA} \mathrm{~h} \mathrm{~g}^{-1}$ after 100 cycles at a high rate of 2C. It also presents excellent rate cyclic performance at different rates. This research has certain application prospects, in line with the contemporary advocacy of new energy sources.

\section{Conflicts of interest}

There are no conflicts to declare.

\section{Acknowledgements}

This work was financially supported by the National Science Foundation of China (51275203); the Key Scientific and Technological Project of Jilin Province (20140204052GX, 20180201074GX); the China Postdoctoral Science Foundation (2017M611321); the Project of Education Department of Jilin Province (JJKH20180130KJ).

\section{Notes and references}

1 G. Zhang, S. Hou and H. Zhang, Adv. Mater., 2015, 27, 24002405.

2 F. Li, L. Yang and G. Xu, J. Alloys Compd., 2013, 577, 663-668.

3 P. Ramu, P. M. Anbarasan and R. Ramesh, Mater. Lett., 2014, 122, 230-233.

4 K. T. Park, F. Xia and S. W. Kim, J. Phys. Chem. C, 2013, 117, 1037-1043.

5 Q. Xie, J. Li and Q. Tian, J. Mater. Chem., 2012, 22, 1354113547.

6 G. H. An, D. Y. Lee and H. J. Ahn, ACS Appl. Mater. Interfaces, 2017, 9, 12478-12485.

7 Y.Song, Y. Chen and J. Wu, J. Alloys Compd., 2017, 694, 12461253.

8 S. M. Abbas, S. T. Hussain and S. Ali, J. Mater. Sci., 2013, 48(16), 5429-5436.

9 X. Shen, D. Mu and S. Chen, ACS Appl. Mater. Interfaces, 2013, 5(8), 3118-3125.

10 G. T. K. Fey, D. C. Lee, Y. Y. Lin and T. P. Kumar, Synth. Met., 2003, 139, 71-80.

11 W. B. Xing, R. A. Dunlap and J. R. Dahn, J. Electrochem. Soc., 1998, 145, 62-70.

12 G. T. K. Fey and C. L. Chen, J. Power Sources, 2001, 97/98, 4751.

13 E. Peleda, V. Eshkenazi and Y. Rosenberg, J. Power Sources, 1998, 76, 153-158.

14 W. B. Xing, J. S. Xue, T. Zheng, A. Gibaud and J. R. Dahn, J. Electrochem. Soc., 1996, 143, 3482-3491.
15 J. Hou, C. Cao, X. Ma, F. Idrees, B. Xu, X. Hao and W. Lin, Sci. Rep., 2014, 4, 7260-7265.

16 R. Pode, Renewable Sustainable Energy Rev., 2016, 53, 14681485.

17 C. Yuan, H. Lin and H. Lu, Appl. Energy, 2016, 178, 260-268. 18 Y. Gao, L. Li, Y. M. Jin, Y. Wang, C. J. Yuan, Y. J. Wei, G. Chen, J. J. Ge and H. Y. Lu, Appl. Energy, 2015, 153, 41-47. 19 K. Yu, J. Li and H. Qi, ChemistrySelect, 2017, 2, 3627-3632.

20 Z. Li, Z. Xu and X. Tan, Energy Environ. Sci., 2013, 6, 871-878.

21 A. H. Lu, W. C. Li and G. P. Hao, Angew. Chem., Int. Ed., 2010, 2, 1615-1618.

22 R. J. White, K. Tauer and M. Antonietti, J. Am. Chem. Soc., 2010, 132, 17360-17363.

23 L. Guo, J. Zhang and Q. He, Chem. Commun., 2010, 46, 71277129.

24 W. Yu, X. Chen and W. Mei, Appl. Surf. Sci., 2017, 4, 129-138. 25 C. He, S. Wu and N. Zhao, ACS Nano, 2013, 7, 4459-4469.

26 D. Pan, S. Wang and B. Zhao, Chem. Mater., 2009, 21, 31363142.

27 S. Zhu, J. Li and X. Deng, Adv. Funct. Mater., 2017, 27, 1605017.

28 W. Jie, H. Zhao and X. Liu, Electrochim. Acta, 2011, 56, 64416447.

29 M. H. Jung, J. Colloid Interface Sci., 2017, 505-631.

30 M. Sevilla and A. B. Fuertes, Carbon, 2009, 47(9), 2281-2289.

31 H. Köse, Ş. Karaal and A. O. Aydın, J. Power Sources, 2015, 295, 235-245.

32 Z. Ren, Z. Wang and C. Chen, Electrochim. Acta, 2014, 146, 52-59.

33 J. H. Lee, K. H. Ko and B. O. Park, J. Cryst. Growth, 2003, 247, 119-125.

34 Y. Sharma, N. Sharma and G. Subba Rao, Adv. Funct. Mater., 2007, 17, 2855-2861.

35 Q. S. Xie, Y. T. Ma, X. P. Wang, D. Q. Zeng, L. S. Wang, L. Q. Mai and D. L. Peng, ACS Nano, 2016, 10, 1283-1291.

36 J. Liu, Y. Li and X. Huang, Adv. Funct. Mater., 2008, 18, 14481458.

37 R. Guo, W. Yue and Y. An, Electrochim. Acta, 2014, 135, 161167.

38 Z. Chen, R. Wu and H. Wang, Chem. Eng. J., 2017, 326, 180190.

39 J. Wu, C. Chen and Y. Hao, Colloids Surf., A, 2015, 468, 17-21. 40 Y. Zou, Z. Qi and Z. Ma, J. Electroanal. Chem., 2017, 788, 184191.

41 Q. Xie, X. Zhang, X. Wu, H. Wu, X. Liu, G. Yue, Y. Yang and D.-L. Peng, Electrochim. Acta, 2014, 125, 659-665.

42 X. Y. Shen, D. B. Mu, S. Chen, R. Huang and F. Wu, J. Mater. Chem. A, 2014, 2(12), 4309-4315.

43 L. Lu, H. Wang, J. G. Wang, et al., J. Mater. Chem. A, 2017, 5, 2530 .

44 Q. Xie, Y. Ma, D. Zeng, L. Wang, G. Yue and D. L. Peng, Sci. Rep., 2015, 5, 8351.

45 Q. S. Xie, Y. T. Ma, X. Q. Zhang, L. S. Wang, G. H. Yue and D. L. Peng, J. Alloys Compd., 2015, 619, 235-239. 